Jurnal Informatika dan Rekayasa Perangkat Lunak (JATIKA)
Vol. 2, No.3, September 2021, page-page. 368 374
ISSN 2723-3367
E-ISSN 2797-3492
available online at:http://jim.teknokrat.ac.id/index.php/informatika

\title{
RANCANG BANGUN SISTEM PERPUSTAKAAN DIGITAL (STUDI KASUS : SMK 1 BANDAR LAMPUNG)
}

\author{
Firnando Siyasih \\ Universitas Teknokrat Indonesia \\ firnando_siyasih@teknokrat.ac.id
}

Published: 30 September 2021

\begin{abstract}
State Vocational High School 1 Bandar Lampung several activities have used computers, but especially in the processing of library data is still done manually, every month officers have to look at the book data and calculate the number of borrowers per day to make monthly reports, it is very retang against data damage, the problem caused is when going to make monthly report officers often have difficulty if there are documents that are damaged or lost. because the officer does not have a backup of the daily report data archive. Based on these problems, the system is designed to be able to develop and implement digital libraries that can be accessed through the website so as to improve the quality of library services without limited space and time. The digital library is expected to facilitate students in the process related to the library. Because the library will be created utilizing Web-based technology. With the user's website will be easier in finding a collection of books, scientific journals, and others needed by each member of the library. In addition, the website can also be accessed anywhere, anytime, and anyone without having to come to the location of smk negeri 1 Bandar Lampung library.
\end{abstract}

Keywords: E-Library, Library, Website.

\begin{abstract}
Abstrak
Sekolah Menengah Kejuruan Negeri 1 Bandar Lampung ada beberapa kegiatan yang telah menggunakan komputer, namun khususnya pada pengolahan data perpustakaan masih dilakukan secara manual, setiap bulan petugas harus melihat data buku dan menghitung jumlah peminjam per hari untuk membuat laporan bulanan, hal tersebut sangat retang terhadap kerusakan data, masalah yang ditimbulkan yakni ketika akan membuat laporan bulanan petugas sering kali mengalami kesulitan bila ada dokumen yang rusak atau hilang karna petugas tidak memiliki cadangan arsip data laporan harian. Berdasarkan permasalahan tersebut maka di rancang sistem agar dapat mengembangkan dan mengimplementasikan perpustakaan digital yang dapat di akses melalui website sehingga dapat meningkatkan kualitas pelayanan perpustakaan tanpa terkendala terbatasnya ruang dan waktu. Dengan adanya perpustakaan digital diharapkan akan mempermudah siswa dalam proses yang berkaitan dengan perpustakaan. Sebab Perpustakaan yang akan dibuat memanfaatkan teknologi yang berbasis Web. Dengan website pengguna akan lebih mudah dalam mencari kolekksi buku, jurnal ilmiah, dan lainnya yang dibutuhkan oleh setiap anggota perpustakaan. Selain itu website juga dapat diakses dimana saja, kapan saja, dan siapa saja tanpa harus datang ke lokasi perpustakaan SMK Negeri 1 Bandar Lampung.
\end{abstract}

Kata Kunci: E-Library, Perpustakaan, Website.

To cite this article:

Firnando Siyasih. (2021). RANCANG BANGUN SISTEM PERPUSTAKAAN DIGITAL (STUDI KASUS : SMK 1 BANDAR LAMPUNG).

Jurnal Informatika dan Rekayasa Perangkat Lunak, Vol(2) No(3), 368-374.

\section{PENDAHULUAN}

Teknologi informasi merupakan salah satu teknologi yang sedang berkembang pesat pada saat ini. Dengan kemajuan teknologi informasi, pengaksesan terhadap data atau informasi yang tersedia dapat berlangsung dengan cepat, efisien serta akurat (Lathifah, 2021; Rahmanto \& Fernando, 2019; Septilia et al., 2020). 
Perkembangan ilmu dan teknologi mendorong berkembangnya sistem administrasi berbasis teknologi informasi. Hal tersebut juga merambah dalam pengelolaan sistem perpustakaan. Teknologi Informasi dan Komunikasi, dapat di artikan yaitu payung besar terminologi yang mencakup seluruh peralatan teknis untuk memproses dan menyampaikan informasi. Kegiatan pemanfaatan teknologi informasi dan komunikasi tentu berperan dalam perpustakaan digital (Megawaty, Alita, et al., 2021; Setiawansyah et al., 2021).

Perpustakaan digital terdiri dari dua kata yaitu perpustakaan dan digital, perpustakaan memiliki arti sebuah koleksi buku dan majalah yang dibiayai dan dioperasikan oleh sebuah kota atau institusi, serta dimanfaatkan oleh masyarakat yang rata-rata tidak mampu membeli sekian banyak buku atas biaya sendiri. Digital yaitu penggambaran dari suatu keadaan bilangan yang terdiri dari angka 0 dan 1 atau off dan on (bilangan biner), disamping itu pemanfaatan green computing juga berperan penting bagi teknologi informasi dan komunikasi. Green computing itu sendiri yaitu sutu ilmu atau penerapan tentang bagaimana kita menggunakan sumber daya komputer atau perangkat elektronik yang kita miliki secara efisien dan ramah lingkungan, namun di tengah pesatnya perkembangan teknologi informasi yang mampu mengakses data atau informasi yang tersedia dengan cepat, efisien, serta akurat, nampak kondisi umum perpustakaan justru berkebalikan. Sebagian besar perpustakaan belum menggunakan teknologi informasi dan masih menerapkan sistem basis data manual yang semua proses transaksinya ditulis pada kertas. Tentu saja penggunaan sistem basis data manual tersebut dalam pengaksesan data atau informasinya akan lambat, kurang efisien bahkan data atau informasi belum tentu terjamin akurasinya (Megawaty, Damayanti, et al., 2021; Sanjaya \& Bakri, 2020; Styawati \& Ariany, 2021).

Perpustakaan digital yang mendukung Green Computing merupakan suatu perpustakaan di mana seluruh isi koleksi dan proses pengelolaan serta layanannya tersebut berupa kumpulan data dalam bentuk digital. Perkembangan perpustakaan digital bagi pengelola perpustakaan dapat membantu pekerjaan di perpustakaan melalui fungsi otomasi perpustakaan, sehingga proses pengelolaan perpustakaan lebih efektif dan efisien. Fungsi otomasi perpustakaan menitik beratkan pada bagaimana mengontrol sistem administrasi layanan secara otomatis atau terkomputerisasi (Ahdan \& Setiawansyah, 2021; Damayanti et al., 2020; Nugroho et al., 2021). Sedangkan bagi pengguna dapat membantu mencari sumber informasi yang diinginkan dengan menggunakan catalog on-line yang dapat diakses melalui intranet maupun internet, sehingga pencarian informasi dapat dilakukan kapan dan dimana pun ia berada. Misal penerapan Green Computing yaitu tidak harus selalu membeli komputer baru, gunakan komputer lama yang masih dapat di pakai, Gunakan layar monitor sesuai dengan kebutuhan, Gunakan monitor LCD daripada CRT karena lebih hemat energy, Matikan komputer/alat-alat lain yang tidak bekerja pada malam hari maupun akhir minggu, Optimalisasi penggunaan komputer dan minimalkan penggunaan komputer untuk hal-hal yang tidak penting (Amarudin et al., 2020; Mindhari et al., 2020).

Berdasarkan wawancara dan observasi yang dilakukan peneliti pada Petugas perpustakaan SMK Negeri 1 Bandar Lampung peneliti mendapatkan data diantaranya, seluruh anggota perpustakaan yakni 847 angggota aktif, dengan fasilitas perpustakaan yakni 8 buah kursi dan 3 buah meja untuk membaca buku, dengan luas ruangan $7 \mathrm{~m} \times 6 \mathrm{~m}$, melihat kondisi dan tingginya kebutuhan akan perpustakaan bagi setiap mahasiswa peneliti menyimpulkan bahwa didalam perpustakaan SMK Negeri 1 Bandar Lampung tidak memadai untuk memanfaatkan fasilitas SMK Negeri 1 Bandar Lampung tersebut. Sebagai upaya mendukung green computing di SMK Negeri 1 Bandar Lampung maka peneliti akan merancang dan membangun sebuah perpustakaan digital, melihat kondisi saat ini sangat terbatas, terutama dalam proses Peminjaman buku masih secara manual dan juga jumlah siswa melebihi jumlah buku yang tersedia di perpustakaan. Selain itu luas ruangan dan fasilitas pembaca buku didalam perpustakaan yang juga tidak memadai untuk menampung kebutuhan setiap siswa siswa yang ada di SMK Negeri 1 Bandar Lampung. Dengan adanya perpustakaan digital diharapkan akan mempermudah mahasiswa dalam proses yang berkaitan dengan perpustakaan. Sebab Perpustakaan yang akan dibuat memanfaatkan teknologi yang berbasis Web. Dengan website pengguna akan lebih mudah dalam mencari kolekksi buku, jurnal ilmiah, dan lainnya yang dibutuhkan oleh setiap anggota perpustakaan. Selain itu website juga dapat diakses dimana saja, kapan saja, dan siapa saja tanpa harus datang ke lokasi perpustakaan SMK Negeri 1 Bandar Lampung (Budiman et al., 2019; Destiningrum \& Adrian, 2017).

\section{TELAAH PUSTAKA \\ Digital Library}

Digital Library atau perpustakaan elektronik atau juga dikenal dengan perpustakaan maya adalah sebuah sistem informasi yang terdiri dari perangkat keras (hardware) dan perangkat lunak (software), pengelolaan, pelayanan serta penyediaan (akses) informasinya dilakukan dengan menggunakan perangkat elektronis yang berupa komputer. Jika dalam perpustakaan konvensional, bahan-bahan pustaka tersimpan dalam rak-rak 
penyimpanan dengan kodifikasi $($ DDC $=$ Dewey Decimal Classification $)$, tersedia meja/laci katalog untuk penelusuran bahan pustaka, ada bagian sirkulasi, ada ruang baca, dan lain-lain. Dalam perpustakaan elektronik, komponen-komponen tersebut tetap ada dalam pengertian tersedia tetapi tidak hadir dalam bentuk fisik (disebut maya) yang umumnya ada dalam perpustakaan konvensional. Perpustakaan elektronik merupakan provider atau penyedia informasi, transaksi atau layanan informasinya bersifat elektronik, serta menyediakan bahan-bahan pustaka (item) selain dalam bentuk data elektronik juga dalam bentuk yang lain seperti yang umumnya ada dalam perpustakaan konvensional. Perpustakaan elektronik merupakan salah satu alternatif dalam menyediakan sumber informasi untuk kegiatan pembelajaran jarak jauh (distance learning), mengingat user atau pengguna perpustakaan berada di tempat yang tidak diketahui keberadaannya. Ini dimungkinkan dengan adanya teknologi internet yang sudah berkembang dengan sangat pesat dewasa ini. User dalam memperoleh informasi, selain menggunakan saluran elektronis seperti melalui komputer dan telepon juga dapat memperolehnya melalui layanan lain seperti melalui jaringan layanan pos atau user juga bisa datang langsung ke tempat di mana sumber informasi tersebut berada.

\section{METODE PENELITIAN}

\section{Teknik Pengumpulan Data}

Metode yang digunakan dalam menyelesaikan adalah sebagai berikut

1. Wawancara (Interview) Merupakan metode yang dilakukan dengan cara wawancara langsung dengan Petugas Perpustakaan.

2. Merupakan metode yang dilakukan dengan cara mengamati secara langsung objek dan permasalahan yang terjadi pada perpustakaan, terutama yang berhubungan dengan permasalahan yang ada di perpustakaan tersebut.

3. Tinjauan Pustaka (Library Research) Membaca dan mempelajari literatur buku-buku pedoman atau dengan mengutip dari tugas akhir, browsing internet yang bersangkutan dengan masalah yang dibahas (Darwis et al., 2019; Listiono et al., 2021; Riskiono \& Reginal, 2018).

\section{Analisis Sistem}

Analisis sistem menggunakan analisis PIECES (Performance, Information, Economy, Control, Efficiency, and Service) yaitu sebagai berikut :

1. Performance (Kinerja) Pada tahap ini akan dilakukan analisis terhadap sistem lama yang kemudian akan ditemukan beberapa kelemahan dan kelebihan yang akan menjadi pertimbangan dirancangnya sistem baru. Analisis kinerja ini akan dilakukan dengan menganalisa perpustakaan SMK Negeri 1 Bandar Lampung.

2. Information (informasi) Analisis informasi menyangkut keakuratan informasi yang dihasilkan. Keterbatasan informasi yang dihasilkan dari sistem yang ada saat ini berdampak pada kemampuan sistem dalam menghasilkan laporan.

3. Analisis Economy dilakukan guna mengukur efektifitas suatu sistem berdasarkan nilai ekonominya. Agar dalam pelaksanaannya tidak terjadi kerugian dalam Perpustakaan. Tabel 3 menampilkan hasil analisis Economy pada sistem yang sedang berjalan.

4. Masalah keamanan sangat penting dalam meningkatkan kinerja sistem agar lebih terkontrol.Hal ini untuk meningkatkan kinerja sistem, mencegah atau mendeteksi kesalahan sistem, dan menjamin keamanan data dan informasi katalog buku.

5. Efisiensi erat hubungannya dengan sumber daya yang dapat digunakan semaksimal mungkin sehingga tidak terjadi pemborosan. Keberadaan sistem yang masih konvensional berdampak pada kecepatan proses dan penyajian laporan yang tidak efisien.

6. Pelayanan dari segi informasi mempunyai sasaran baik bagi siswa atau pihak terkait. Koordinasi yang belum teratur mengenai pengolahan data, penyimpanan laporan serta dokumentasi akan menurunkan kualitas pelayanan yang pada akhirnya akan mengakibatkan kerja dari lembaga pendidikan tersebut menjadi terganggu, sehingga perlu ditingkatkan. 


\section{HASIL DAN PEMBAHASAN}

\section{Tampilan Halaman Utama Anggota}

Halaman utama anggota ini berisi formlogin (jika belum login) anggota tidak bias membaca buku dan mendownloads buku, dan juga terdapat form pencarian buku serta daftar buku yang sering di kunjungi,di samping daftar buku terdapat gambar (slide show)aktifitas sekolah dan gambar buku terfavorit.

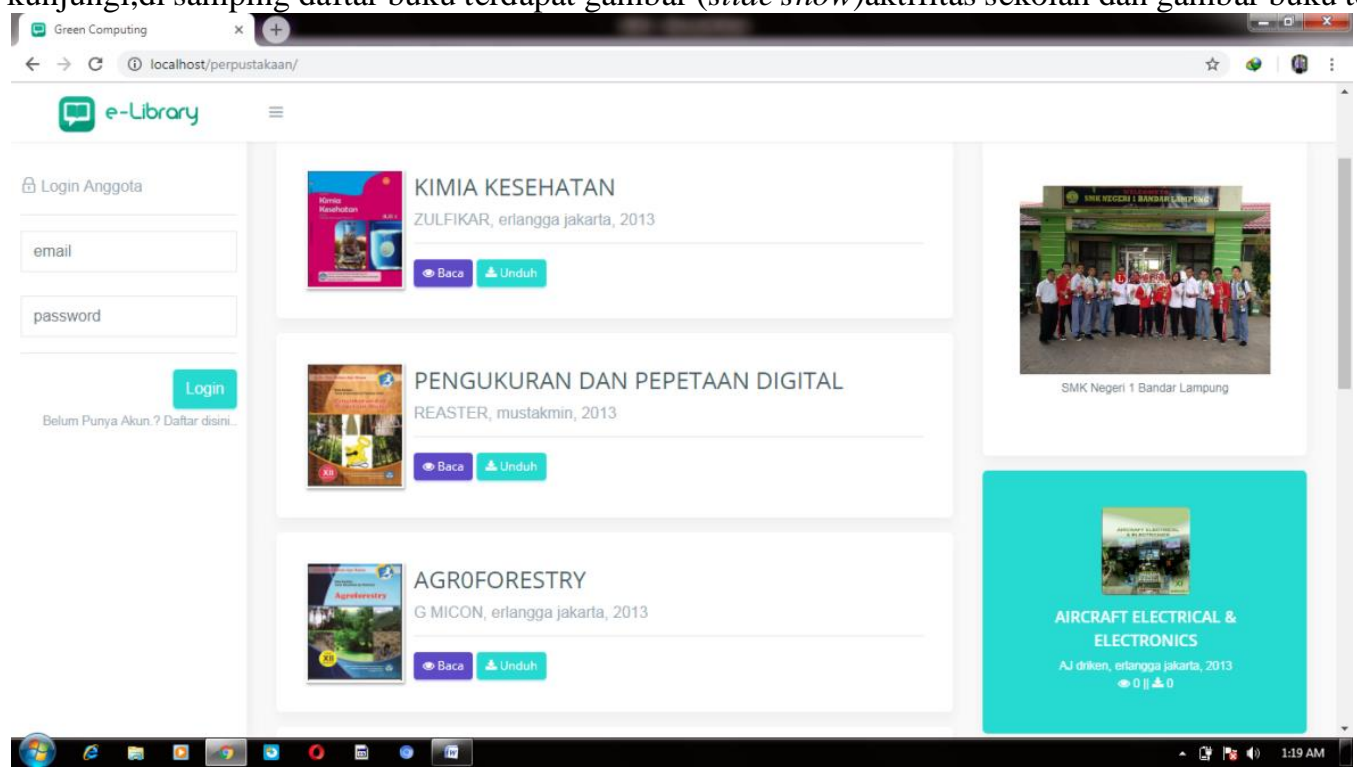

Gambar 1. Tampilan Halaman Utama Anggota

\section{Tamplian Halaman Utama/Beranda anggota}

Halaman utama/beranda ini berisi formberanda,riwayat,favorit dan jugaform pencarian buku serta daftar buku dan di samping terdapat gambar aktifitas sekolah dan gambar buku terpavorit.

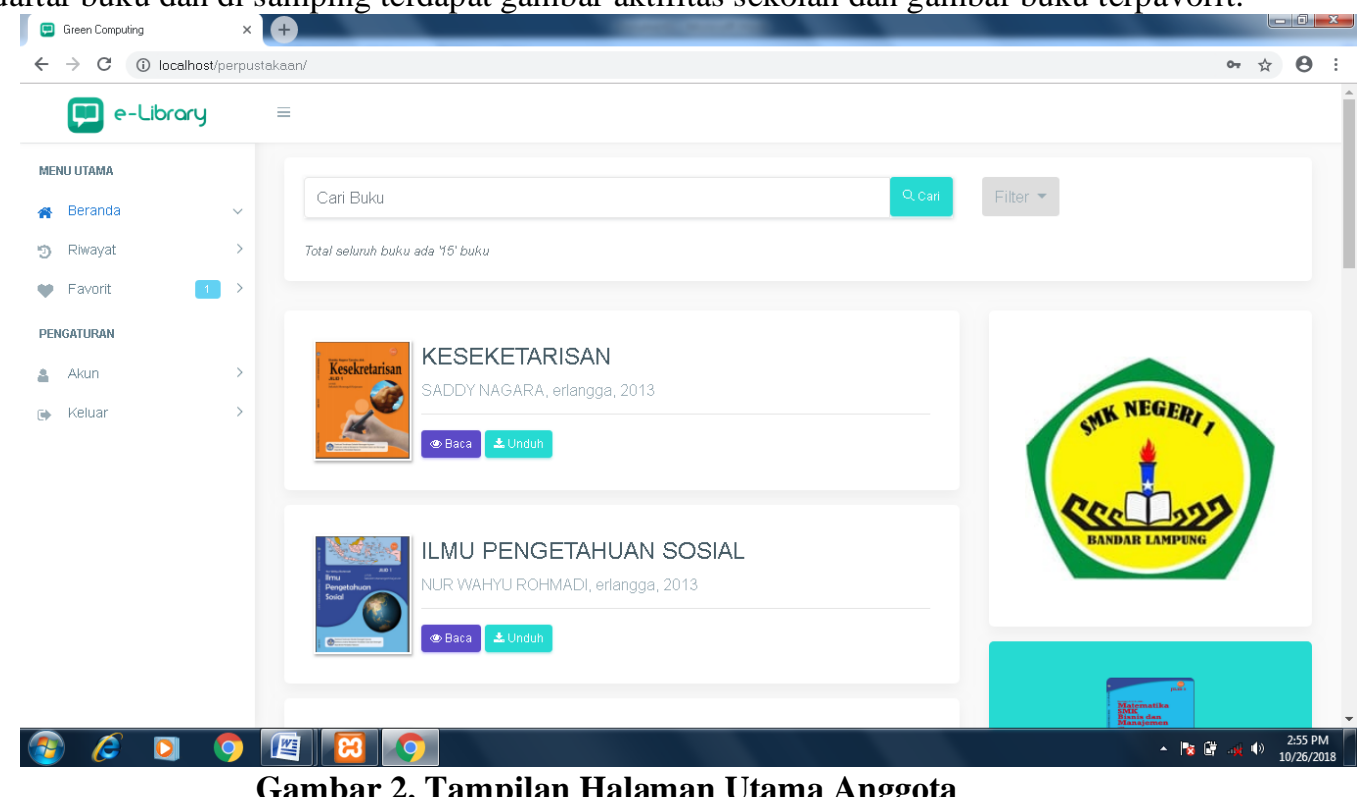

Gambar 2. Tampilan Halaman Utama Anggota

\section{Tampilan Halaman Riwayat}

Tampilan ini berisi daftar aktivitas anggota yaitu aktivitas membaca dan mengunduh buku didalam aktifitas tersebut terdapat nama buku yang di unduh, jenis buku dan waktu mengunduh buku tersebut. 


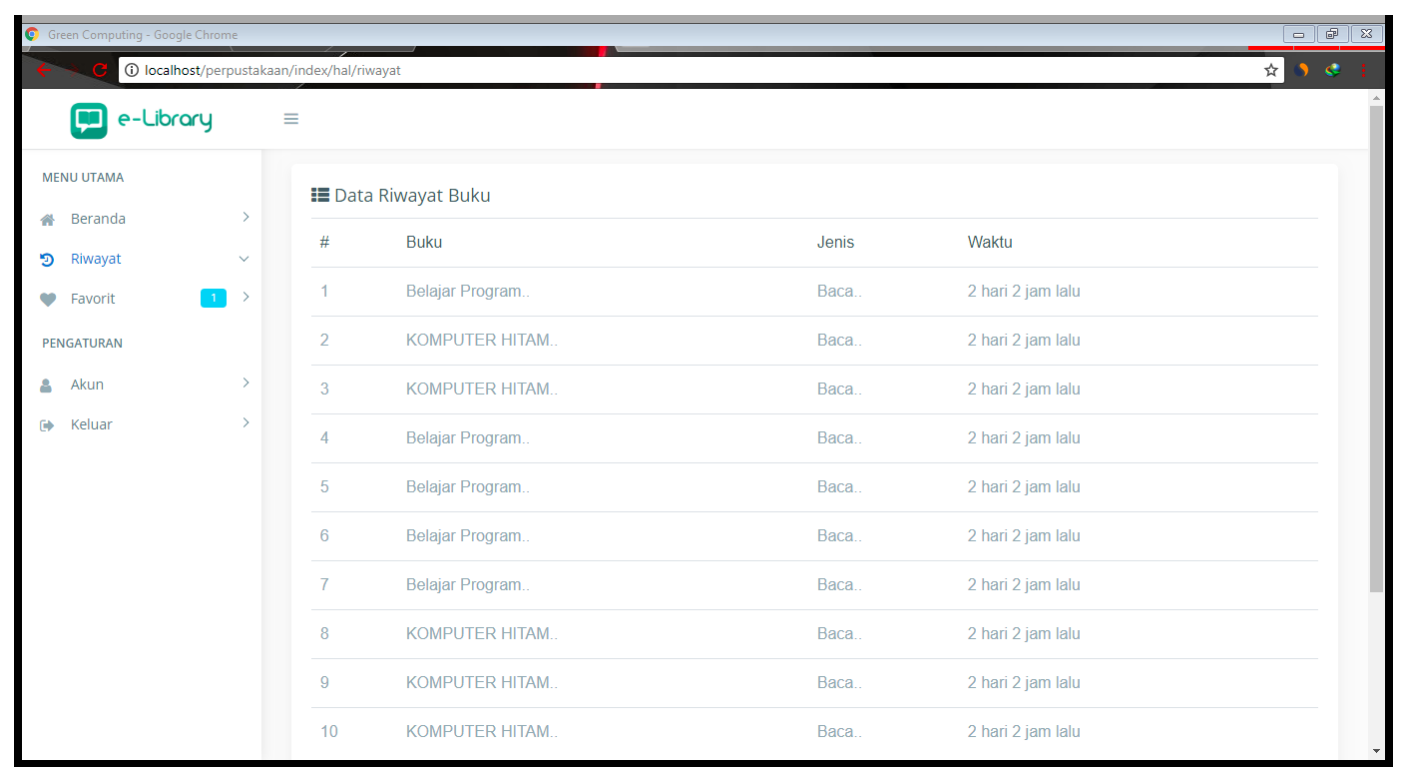

\section{Gambar 3. Tampilan Halaman Riwayat Anggota}

\section{Tampilan Halaman Lihat/Baca Buku}

Tampilan form bacaa buku, tampilan ini menampilkan buku yang dibaca, lalu di samping form baca buku terdapat dua batem, batem pertama digunakan jika ingin mendonload batem kedua di gunakan untuk menampilkan buku favorit di halaman beranda user.

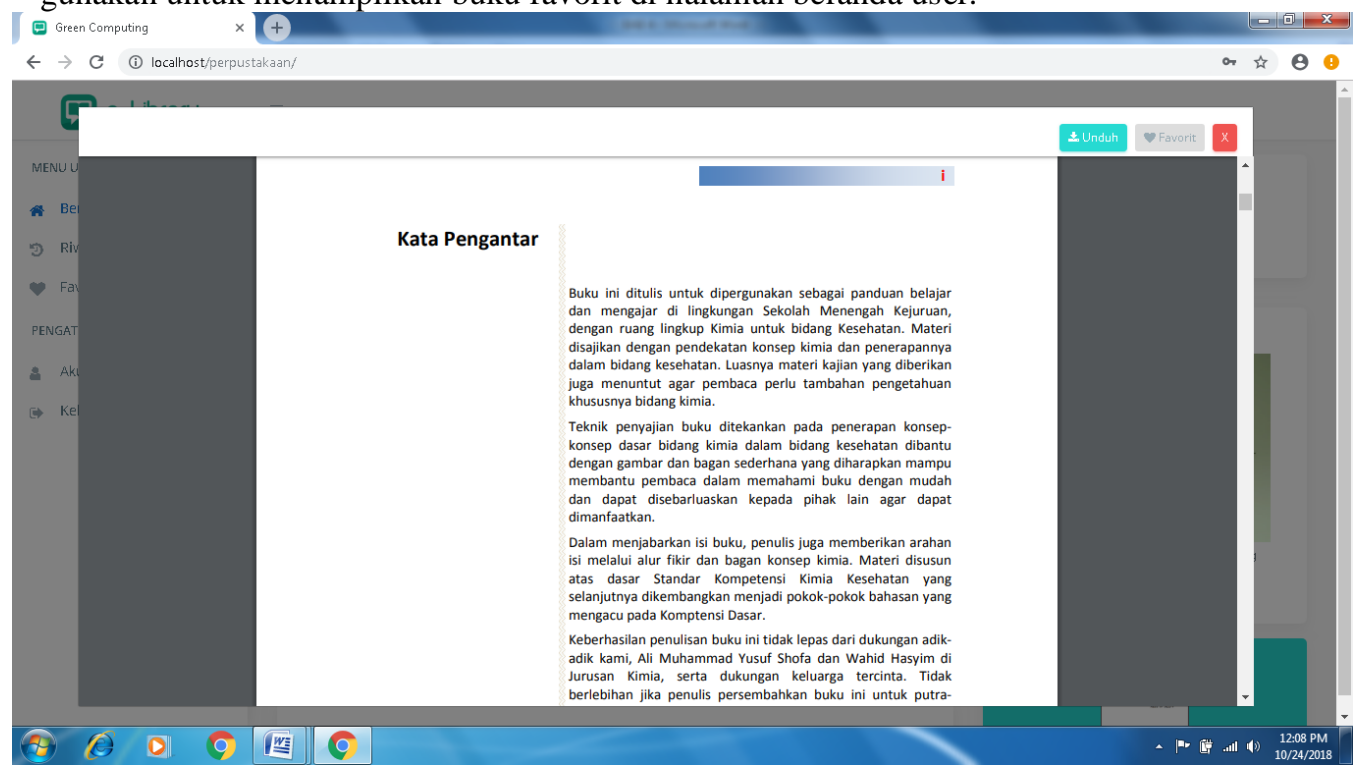

Gambar 4. Tampilan Halaman Baca Buku

\section{Hasil Pengujian Functionality}

Untuk pengujian aspek functionality menggunakan kuesioner yang berisi daftar fungsi yang dimiliki aplikasi (Lestari et al., 2020; Yana et al., 2020). Kuisioner diisi oleh orang yang memiliki keahlian dalam bidang software engineering. Adapun hasil pengujian aspek functionality dapat dilihat pada tabel berikut ini 
Tabel 1. Hasil pengujian aspek functionality

\begin{tabular}{|c|c|c|c|c|}
\hline \multirow[t]{2}{*}{ No } & \multirow{2}{*}{ Fitur } & \multirow{2}{*}{ Fungsi } & \multicolumn{2}{|c|}{ Hasil Pengujian } \\
\hline & & & Sukses & Gagal \\
\hline 1 & Menu & $\begin{array}{l}\text { Menampilkan halaman MenuUtama. } \\
\text { login }\end{array}$ & 1 & - \\
\hline 2 & \multirow[t]{3}{*}{ Beranda } & Menampilkan halaman daftar buku & 1 & - \\
\hline 3 & & $\begin{array}{l}\text { Menampilkan slide show aktifitas } \\
\text { sekolah }\end{array}$ & 1 & - \\
\hline 4 & & $\begin{array}{l}\text { Menampilkan slite show defter buku } \\
\text { pavorit }\end{array}$ & 1 & - \\
\hline 5 & \multirow[t]{2}{*}{ Riwayat } & $\begin{array}{l}\text { Menampilkan riwayat anggota } \\
\text { mengakses website }\end{array}$ & 1 & - \\
\hline 6 & & $\begin{array}{l}\text { Menampilkan riwayat anggota } \\
\text { mengakses buku }\end{array}$ & 1 & - \\
\hline 7 & Pavorit & $\begin{array}{l}\text { Menampilkan semua buku yang sudah } \\
\text { Ditandai pavorit }\end{array}$ & 1 & - \\
\hline 16 & Pencarian & Menampilkan buku yang di cari anggota perpustakaan & 1 & - \\
\hline 18 & Akun & Menampilkan username anggota & 1 & - \\
\hline
\end{tabular}

Berdasarkan angket yang diisi oleh 1 (satu) orang yang memiliki keahlian dalam bidang software engineering, menunjukan hasil bahwa fungsi-fungsi pada aplikasi dapat berjalan dengan benar, tidak adanya tombol yang tidak berfungsi dan tombol memunculkan perintah yang sesuai.

\section{SIMPULAN}

Berdasarkan pembahasan dari penulisan laporan skripsi tentang Perpustakaan digital sebagai upaya pendukung green computing di SMK Negeri 1 Bandar Lampung menggunakan website (studi kasus :SMK Negeri 1 Bandar Lampung), dapat diambil kesimpulan yaitu sebagai upaya memberikan kontribusi terhadap ilmu pengetahuan pada bidang teknologi yang ramah lingkungan khususnya dalam melakukan proses pelayanan perpustakaan digital pada SMK Negeri 1 Bandar Lampung. Hasil pengujian terhadap sistem menggunakan metode black-bok testing disini pengujian dilakukan dengan cara mengimputkan data pada sistem sehingga akan muncul hasil dari pengujian.

\section{REFERENSI/DAFTAR PUSTAKA}

Ahdan, S., \& Setiawansyah, S. (2021). Android-Based Geolocation Technology on a Blood Donation System (BDS) Using the Dijkstra Algorithm. IJAIT (International Journal of Applied Information Technology), 1-15.

Amarudin, A., Saputra, D. A., \& Rubiyah, R. (2020). Rancang Bangun Alat Pemberi Pakan Ikan Menggunakan Mikrokontroler. Jurnal Ilmiah Mahasiswa Kendali Dan Listrik, 1(1), 7-13.

Budiman, A., Wahyuni, L. S., \& Bantun, S. (2019). Perancangan Sistem Informasi Pencarian Dan Pemesanan Rumah Kos Berbasis Web (Studi Kasus: Kota Bandar Lampung). Jurnal Tekno Kompak, 13(2), 24-30.

Damayanti, D., Akbar, M. F., \& Sulistiani, H. (2020). Game Edukasi Pengenalan Hewan Langka Berbasis Android Menggunakan Construct 2. Jurnal Teknologi Informasi Dan Ilmu Komputer, 7(2), 275-282.

Darwis, D., Pasaribu, A. F., \& Surahman, A. (2019). Sistem Pencarian Lokasi Bengkel Mobil Resmi Menggunakan Teknik Pengolahan Suara dan Pemrosesan Bahasa Alami. Jurnal Teknoinfo, 13(2), 71-77.

Destiningrum, M., \& Adrian, Q. J. (2017). Sistem Informasi Penjadwalan Dokter Berbassis Web Dengan Menggunakan Framework Codeigniter (Studi Kasus: Rumah Sakit Yukum Medical Centre). Jurnal Teknoinfo, 11(2), 30. https://doi.org/10.33365/jti.v11i2.24

Lathifah, S. (2021). Analisis Penerimaan Aplikasi Web Engineering Pelayanan Pengaduan Masyarakat Menggunakan Technology Acceptance Model. JATISI (Jurnal Teknik Informatika Dan Sistem Informasi), 8(1), 299-311.

Lestari, I. D., Samsugi, S., \& Abidin, Z. (2020). Rancang Bangun Sistem Informasi Pekerjaan Part Time Berbasis Mobile Di Wilayah Bandar Lampung. TELEFORTECH: Journal of Telematics and Information Technology, 1(1).

Listiono, E. D., Surahman, A., \& Sintaro, S. (2021). ENSIKLOPEDIA ISTILAH GEOGRAFI MENGGUNAKAN METODE SEQUENTIAL SEARCH BERBASIS ANDROID STUDI KASUS: SMA TELADAN WAY JEPARA LAMPUNG TIMUR. Jurnal Teknologi Dan Sistem Informasi, 2(1), 35-42. 
Megawaty, D. A., Alita, D., \& Dewi, P. S. (2021). PENERAPAN DIGITAL LIBRARY UNTUK OTOMATISASI ADMINISTRASI PERPUSTAKAAN. Journal of Social Sciences and Technology for Community Service (JSSTCS), 2(2), 121-127.

Megawaty, D. A., Damayanti, D., Assubhi, Z. S., \& Assuja, M. A. (2021). APLIKASI PERMAINAN SEB AGAI MEDIA PEMBELAJARAN PETA DAN BUDAYA SUMATERA UNTUK SISWA SEKOLAH DASAR. Jurnal Komputasi, 9(1), 58-66.

Mindhari, A., Yasin, I., \& Isnaini, F. (2020). PERANCANGAN PENGENDALIAN INTERNAL ARUS KAS KECIL MENGGUNAKAN METODE IMPREST (STUDI KASUS: PT ES HUPINDO). Jurnal Teknologi Dan Sistem Informasi, 1(2), 58-63.

Nugroho, N., Rahmanto, Y., Rusliyawati, R., Alita, D., \& Handika, H. (2021). Software Development Sistem Informasi Kursus Mengemudi (Kasus: Kursus Mengemudi Widi Mandiri). J-SAKTI (Jurnal Sains Komputer Dan Informatika), 5(1), 328336.

Rahmanto, Y., \& Fernando, Y. (2019). RANCANG BANGUN SISTEM INFORMASI MANAJEMEN KEGIATAN EKSTRAKURIKULER BERBASIS WEB (STUDI KASUS: SMK MA'ARIF KALIREJO LAMPUNG TENGAH). Jurnal Tekno Kompak, 13(2), 11-15.

Riskiono, S. D., \& Reginal, U. (2018). Sistem Informasi Pelayanan Jasa Tour Dan Travel Berbasis Web (Studi Kasus Smart Tour). Informasi Dan Komputer, 06(02), 51-62.

Sanjaya, E., \& Bakri, M. (2020). Analisis Implementasi Metode Sprint dalam Pengembangan Aplikasi Multiplatform. 1(1), 8392.

Septilia, H. A., Parjito, P., \& Styawati, S. (2020). SISTEM PENDUKUNG KEPUTUSAN PEMBERIAN DANA BANTUAN MENGGUNAKAN METODE AHP. Jurnal Teknologi Dan Sistem Informasi, 1(2), 34-41.

Setiawansyah, S., Adrian, Q. J., \& Devija, R. N. (2021). Penerapan Sistem Informasi Administrasi Perpustakaan Menggunakan Model Desain User Experience. Jurnal Manajemen Informatika (JAMIKA), 11(1), 24-36.

Styawati, S., \& Ariany, F. (2021). Sistem Monitoring Tumbuh Kembang Balita/Batita di Tengah Covid-19 Berbasis Mobile. J. Inform. Univ. Pamulang, 5(4), 490.

Yana, S., Gunawan, R. D., \& Budiman, A. (2020). SISTEM INFORMASI PELAYANAN DISTRIBUSI KEUANGAN DESA UNTUK PEMBANGUNAN (STUDY KASUS: DUSUN SRIKAYA). Jurnal Informatika Dan Rekayasa Perangkat Lunak, 1(2), 254-263. 